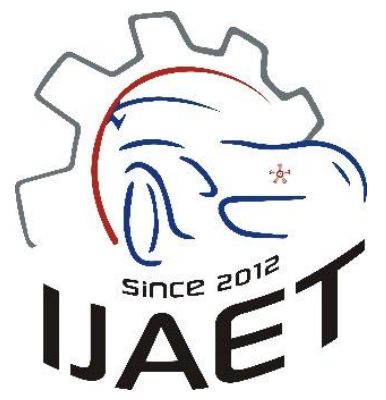

e-ISSN: 2146 - 9067

International Journal of Automotive

Engineering and Technologies

journal homepage: http:// http://dergipark.gov.tr/ijaet

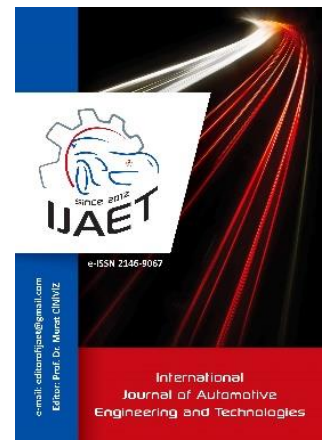

Original Research Article

\title{
Numerical comparative mapping study to evaluate performance of a dual sequential spark ignition engine fueled with ethanol and E85
}

\author{
Ahmet Alper Yontar \\ Department of Automotive Engineering, Tarsus University, Tarsus, Mersin 33400, Turkey
}

\section{ARTICLE INFO \\ * Corresponding author aayontar@tarsus.edu.tr \\ Received: April 24, 2018 \\ Accepted: October 08, 2018 \\ Published by Editorial Board Members of IJAET \\ (C) This article is distributed by Turk Journal Park System under the CC 4.0 terms and conditions.}

\begin{abstract}
The effects of ethanol and E85 usages on engine performance characteristics have been numerically investigated at a dual sequential spark ignition engine. The Honda L13A4 i-DSI (Intelligent-Dual Sequential Ignition) engine (intakeexhaust manifold connections, intake-exhaust lines, intake-exhaust valves, cylinder, cylinder head, piston, spark-plugs, throttle etc.) was modeled in Ricardo-Wave software for ethanol and E85 usages taking into account all components related to the engine. In the analysis, engine speeds ranging from $1000 \mathrm{rpm}$ to $6000 \mathrm{rpm}$ with an increment of $500 \mathrm{rpm}$, throttle angle ranging from $22.5^{\circ}$ to $90^{\circ}$ with an increment of $2.5^{\circ}, 10.8: 1$ compression ratio, 0.9 airfuel ratio were adjusted. In the 1-D model, performance maps were generated using the data obtained as a result of the analyzes. As a result of the study, E85 has been observed to perform better than ethanol usage for the Honda L13A4 i-DSI that the engine designed for the usage of gasoline.

Keywords: Ethanol, E85, 1-D Model, Engine Performance, Engine Mapping, Dual Sequential Ignition
\end{abstract}

\section{Introduction}

The effects of technological advances are also seen in the automotive world. Many studies on vehicle structure, vehicle control systems, powertrain and vehicle engines are being carried out and new R \& D investments are being made in the automotive sector.

Experimental research on internal combustion engines, one of the most important research areas of the automotive field, requires high costs and time-consuming. The importance of numerical modeling studies for internal combustion engine is increasing day by day and numerical modeling studies save time and reduce costs.

The $\mathrm{R} \& \mathrm{D}$ done on the engines focuses on engine performance and engine emissions and continues with increasing momentum every day. All working conditions of the engine are examined in detail by experimental and numerical analysis methods and optimum operation conditions are tried to be determined and controlled.

The effect of many parameters on engine performance and exhaust emissions can be examined ultimately with the modeling software. Examples of these parameters are: loading conditions, compression ratio, combustion mechanisms, alternative fuel additives, alternative fuel usage, combustion chamber geometry, etc.

Engine modeling studies are carried out through 1-D modeling and 3-D modeling methods. In the engine software section, efforts to obtain near- 
realistic results continue every day. In this context, many software is used such as RicardoWave and STAR-CD/es-ice, AVL-Fire, GTPower etc. Through the studies carried out in these software, many results can be obtained about the actual engine behavior.

Usage of alternative fuels in internal combustion engines has been increased day by day. The most widely available and used alternative fuels are ethanol, E85 (Blend of 85\% ethanol and 15\% gasoline by volume) and methanol fuels are the most popular fuel varieties. Approximately 25 million of gallons' ethanol produced at 2016 in the world [1]. Ethanol and its derivatives evaporate faster than the gasoline. In addition to they have much higher octane rating and heat of vaporization than conventional gasoline.

It was conducted several studies on the specified engine operating conditions for ethanol and E85 by this time in the literature.

Johansen et al. [2], investigated the effect of E85 on engine performance, exhaust emissions (especially $\mathrm{OH}$ and soot formation) for a single cylinder optical engine with an outward opening piezo actuated injector and compared from usage of E10. They concluded that E85 led to pool fires on the piston surface which was the only source of soot formation.

Sarjovaara and Larmi [3], used a heavy-duty diesel engine equipped with a common-rail injection system with E85. They injected E85 at low pressure into the intake manifold and modified to fuel injection time. They demonstrated E85 increases $\mathrm{CO}$ and $\mathrm{HC}$ emission but decrease $\mathrm{NO}_{\mathrm{x}}$ emission.

Türköz et al. [4], investigated effects of ignition timing in a spark ignition engine using E85. They measured output performance parameters such as power and efficiency. They determined to the best ignition timing value for best performance and emissions. However, they ascertained that increasing the delay in ignition timing caused poor combustion, more $\mathrm{HC}$ emissions, and fuel consumption.

Sarjovaara, et al. [5], investigated of engine performance and exhaust emissions at E85 usage with direct injected into the cylinder with a common-rail injection system. Their study focused on medium and high load conditions and investigated air temperature in cylinder mixture. They concluded that charge air temperature influenced the ignition delay and the cylinder pressure. They demonstrated that increase of the E85 rate in air-fuel mixture, decreased nitrogen oxide emission and combustion efficiency, but increased carbon monoxide and hydrocarbon emissions.

Wang, et al. [6], investigated eight fuels (gasoline and ethanol compositions) for low and high loads via a single-cylinder direct-injection spark ignition engine. They concluded that at the knock-limited engine loads, splash blended ethanol fuels with a higher ethanol percentage enabled higher engine thermal efficiency.

Huang, et al. [7], investigated charge cooling effect and combustion characteristics of ethanol via CFD modeling and engine tests. They used a gasoline port injection engine equipped with ethanol direct injection system. They verified and compared the simulation results by experimental results. They concluded that $\mathrm{CO}$ and $\mathrm{HC}$ emissions increased due to incomplete combustion and indicated mean effective pressure was increased, combustion initiation duration and major combustion duration were decreased when ethanol ratio was in $0-58 \%$.

Phuangwongtrakul, et al. [8], investigated effects of ethanol-gasoline blends on spark ignition engine performance. They measured brake thermal efficiency, brake torque and brake specific fuel consumption according to different volumetric mixing ratio. Besides, they realized the experimental tests for different engine speeds and throttle openings. They demonstrated that ethanol-gasoline mixing ratio can enhance engine torque output, especially at low engine speed. They specified that the brake thermal efficiency is maximum when the engine operates at $58-73 \%$ of wide open throttle with an engine speed of 2000-2500 rpm. Their study provided a guideline for a suitable ethanolgasoline blend rate at different engine loads and engine speeds.

Nakata et al. [9], examined to the effect of ethanol concentration on thermal efficiency, torque, emissions, and combustion at low temperature for a spark ignition engine. They also investigated combustion characteristics at cold engine conditions. They demonstrated that ethanol improves engine torque and thermal efficiency and reduces $\mathrm{NO}_{\mathrm{x}}$ formation and $\mathrm{HC}$ emissions.

Li et al. [10] investigated to ethanol, butanol and methanol fuels effect on a spark ignition engine 
performance and exhaust gas emissions. The engine parameters are comparatively analyzed for both fuels by theirs. They detected ethanolgasoline blends produce the lowest $\mathrm{HC}$ emission.

Hamilton et al. [11] examined to pre-ignition characteristics of ethanol and E85 at a spark ignition engine. The ethanol pre-ignites at $10^{\circ}$ $20^{\circ}$ lower glow plug temperature than does E85. They detected pre-ignition starts $14^{\circ}$ (E85) to $8^{\circ}$ (ethanol) BTC, a significant loss in indicated mean effective pressure is observed as compared to other pre-ignition starting locations.

Park et al. [12] investigated the influence of ethanol fuel on SI engine performance, thermal efficiency and emissions. They detected the effect of the addition of ethanol on the advance of spark timing, the compression ratio can be raised so that thermal efficiency and engine power output can be improved. For emissions; they demonstrated $\mathrm{HC}$ and $\mathrm{NO}_{\mathrm{x}}$ emission decreased for ethanol and ethanol-gasoline blends usage.

Jin et al. [13] investigated to ethanol-gasoline blends on particulates and un-regulated gaseous emissions characteristics. They used a spark ignition direct injection passenger vehicle. They demonstrated individual HCs, alcohols, and aldehydes emissions strongly increased with E85 fuel. They detected fuel economy and $\mathrm{CO}_{2}$ were related to heating value and ethanol content of the fuels. Their results showed much lower emission characteristic as ethanol contents increased at aromatic HCs emission.

This study, 1-D engine model including intake and exhaust lines was built in Ricardo-Wave software. The engine is sequential spark ignited and fuelled with ethanol and E85. The engine performance maps were investigated for different throttle angles at several engine speeds for both ethanol and E85.

\section{1-D Engine Modelling}

As a result of 1-D numerical modeling of spark ignition engines, the performance values can be obtained more quickly and economically than the test devices. Hence, it has become inevitable for producers and users to turn to numerical analyzes instead of costly and time-consuming engine tests.
In this study, a sequential spark ignition engine was modeled as 1-D with all the elements. Engine parts with specific geometric measurements are created individually with representative elements. The main technical specifications of the modelled sequential spark ignition engine are given in Table 1.

Table 1. Specifications of the engine

\begin{tabular}{lc}
\hline Specification & Description \\
\hline Engine model & Honda L13A4 i-DSI \\
Displacement, cc & 1339 \\
Bore, m & 0.073 \\
Stroke, m & 0.080 \\
Connecting rod length, m & 0.149 \\
Compression ratio & $10.8: 1$ \\
Number of cylinders & 4 \\
Max. torque, Nm/rpm & $119 / 2800$ \\
Max. power, kW/rpm & $63 / 5700$ \\
\hline
\end{tabular}

At first, the measurements of all engine parts were obtained from CMM (Coordinate Measuring Machine) device. Then, the engine modelling phase, each engine components (pistons, cylinders, throttle, air cleaner, valves, ports, engine blocks, intake and exhaust manifolds, fuel line, exhaust line, etc.) are separately formed by defining their properties in Wave software. Afterwards, the parts are assembled to each other, as can been seen Fig 1 . Ignition advance values, engine parts surfaces temperatures, etc. added on "Constants" section in the 1-D engine model for different engine speeds and loads by using the data in common literature [14-15-16]. The 1-D model constants consists of hundreds of data. Some of the constants for the modelled dual sequential spark ignition engine are given in Table 2.

\begin{tabular}{lcc}
\multicolumn{3}{c}{ Table 2. Some of the constants } \\
\hline Data & Unit & Range \\
\hline Speed & rpm & $1000-6000$ \\
Throttle opening & degree & $22.5-90.0$ \\
Air fuel ratio & & $8.2-16.6$ \\
CA50 & degree & $20.0-25.0$ \\
CA1090 & degree & $21.5-28.0$ \\
Injection duration & degree & $40.0-80.0$ \\
Start of injection & degree & $269-319$ \\
Head temperature & $\mathrm{K}$ & $550-640$ \\
Liner temperature & $\mathrm{K}$ & $540-620$ \\
Piston temperature & $\mathrm{K}$ & $500-600$ \\
Intake valve temp. & $\mathrm{K}$ & $312-326$ \\
Exhaust valve temp. & $\mathrm{K}$ & $506-582$ \\
Oil temperature & $\mathrm{K}$ & $358-378$ \\
\hline
\end{tabular}

In the 1-D model, Woschni heat transfer correlation [17] and multi-component Wiebe combustion models [18] are used. For emission calculations following correlations are used: 
Newhall correlation for $\mathrm{CO}$ and $\mathrm{CO}_{2}$ [19], Cheng correlation for $\mathrm{HC}$ formation [20], and Fenimore correlation [21] and Zeldovich formation mechanisms for $\mathrm{NO}_{\mathrm{x}}$ [22].

Woschni accounts for the increase in the gas velocity in the cylinder during combustion. For cylinder bore $d$, instantaneous cylinder gas pressure $P_{1}$, instantaneous cylinder temperature $T_{l}$, instantaneous cylinder volume $V_{l}$, mean piston speed $S_{p m}$, stroke volume $V_{s}$ and gas pressure in the cylinder of the corresponding engine $P_{0}$. The constants $c_{1}$ and $c_{2}$ are 2.28 and 0.00324 , respectively.

The heat transfer coefficient given by Woschni is:

$$
\begin{aligned}
h=110 d^{-0.2} P_{1}^{0.8} T_{1}^{-0.53} & \\
& {\left[c_{1} S_{p m}+c_{2} \frac{V_{s} T_{1}}{P_{1} V_{1}}\left(P-P_{0}\right)\right]^{0.8} }
\end{aligned}
$$

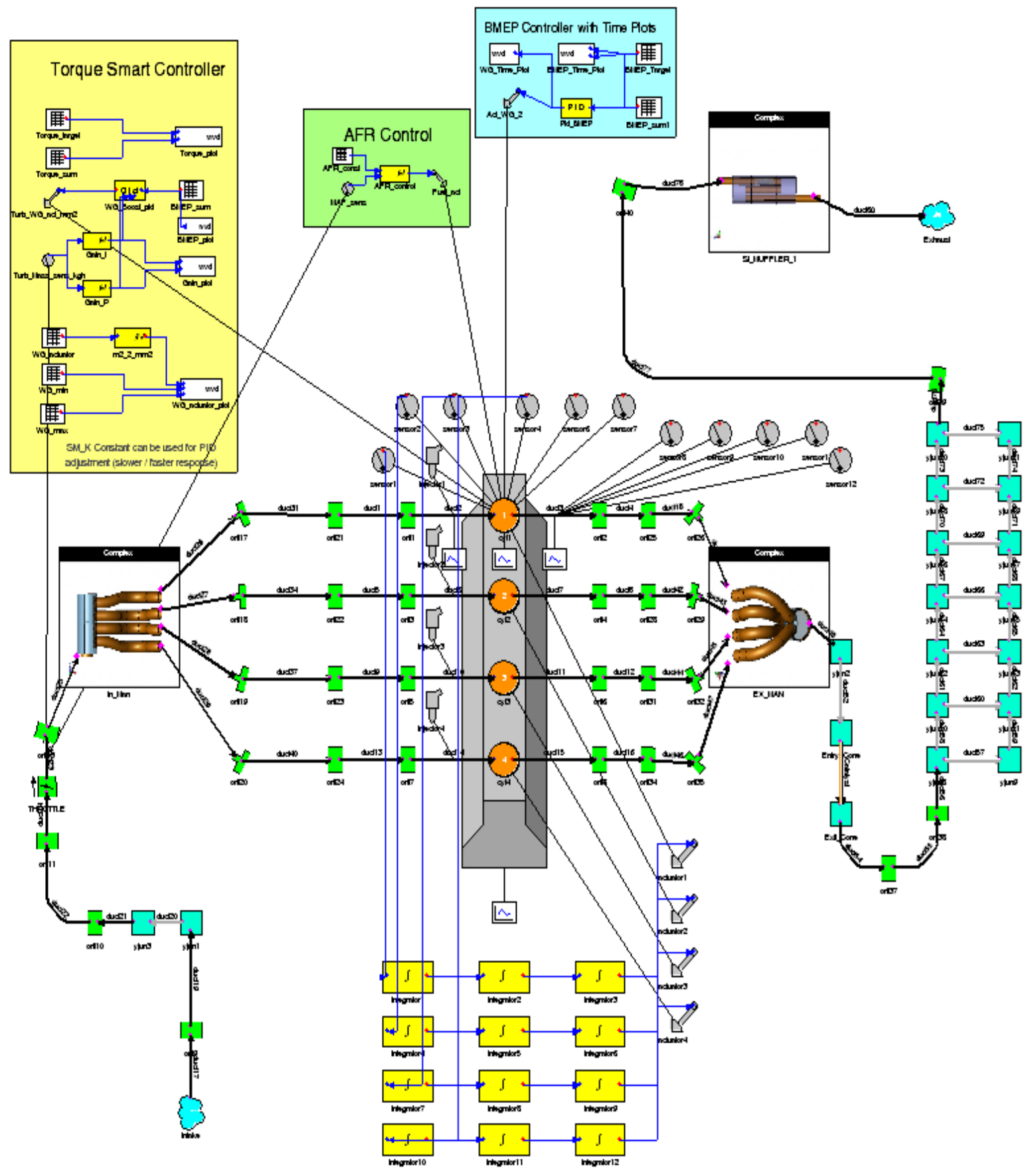

Figure 1. 1-D Engine model

Wiebe struggled with the physical meaning of the exponent $m$ and maximum burn rate to be reached is determined solely by the magnitude of $m$. The Wiebe functions for the nondimensional burn fraction $x$ and its derivative $w$ (burn rate) as functions of time $t$ can now be written as: 


$$
\begin{aligned}
& x=1-e^{-6.908\left(t / t_{d}\right)^{m+1}} \\
& w=\frac{d x}{d t}=\frac{6.908(m+1)}{t_{d}}\left(\frac{t}{t_{d}}\right)^{m} e^{-6.908\left(t / t_{d}\right)^{m+1}}
\end{aligned}
$$

where $t$ is measured from start of combustion and the combustion duration is denoted $t_{d}$.

In the Wiebe combustion model [18]; combustion process contains three parts (premixture, diffusion and tail). The Wiebe combustion model accounts for all cycle characteristics and also considers the thermal decomposition of the combustion products. In this model, the pressure and temperature inside the cylinder vary depending on the crank angle. With the Vibe function, the calculation of the combustion curve for the entire cycle can be carried out if the average burning rate, the relative time of the maximum burning rate and the spraying rate are known.

For whole spark ignition engines, as defined the combustion duration in the Wiebe model ranges from $0.005 \mathrm{~s}$ to $0.016 \mathrm{~s}$.

The ignition advances and combustion mechanisms have been identified using Single Wiebe combustion diagram in Fig. 2.

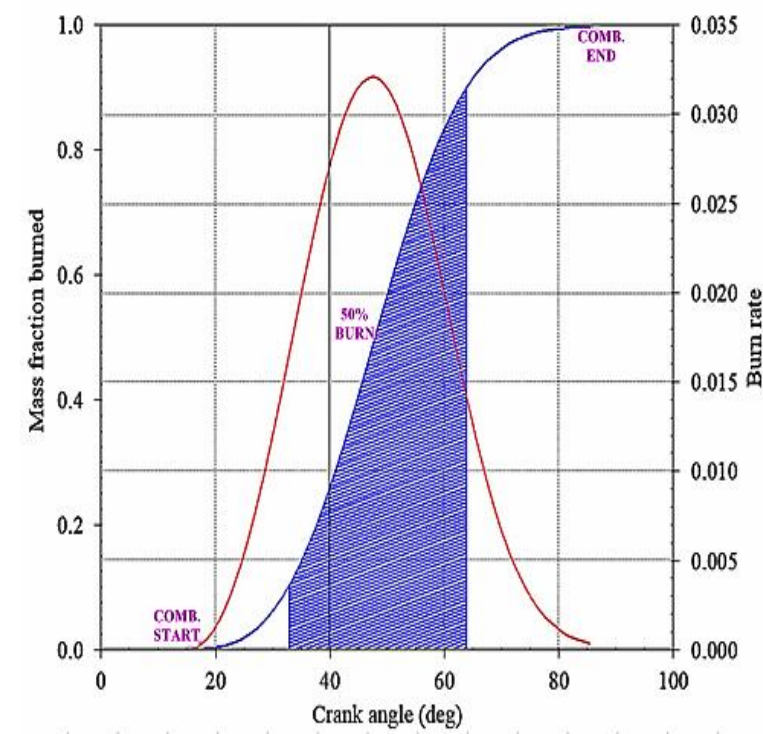

Figure 2. Single Wiebe combustion diagram

For analyzed to engine data on the 1-D engine model, many sensors, actuators and signal processor were located at certain points on the model. The time step multiplier and the convergence criterion were set to 0.1 and 0.001 , respectively.

The analyses were run for 300 engine cycles for each engine speed in order to ensure fully developed steady conditions before reading the data.
The engine 1-D model is built including the entire engine from the beginning of the intake line to the end of the exhaust line as plotted in Fig. 2.

\section{Result and Discussion}

In the analysis, engine speeds ranging from $1000 \mathrm{rpm}$ to $6000 \mathrm{rpm}$ with an increment of 500 $\mathrm{rpm}$, throttle angle ranging from $22.5^{\circ}$ to $90^{\circ}$ with an increment of $2.5^{\circ}, 10.8: 1$ compression ratio, 0.9 air-fuel ratio were adjusted.

The results with respect to engine speeds, throttle angles and different fuels (ethanol and E85) are presented below in mapping plots.

Brake torque maps for ethanol and E85 are given in Fig. 3. The brake torque values are seen from both maps that have increased with throttle angle and these curves lead to parabolic areas in the maps. In natural aspirated engines, torque is reduced due to increased physical losses at higher engine speeds.

It is possible to observe these behaviors in the torque maps using both fuels. The torque for ethanol is about $10 \%$ (that varies with speed) less than E85 (QLHV=29282 kj/kg) because of the lower heating value of ethanol ( $Q_{\mathrm{LHV}}=26830$ $\mathrm{kj} / \mathrm{kg}$ ). The effective torque field for E85 usage is higher than ethanol usage. As a results of this, the brake means effective pressure (BMEP) maps are also low for ethanol as plotted in Fig. 6.

As also plotted Fig. 4, the brake power areas increase with engine speed almost linearly due to more fuel intake into cylinder and as is known, power is a function of fuel consumption for internal combustion engines. The brake power values also increase with the throttle opening angle.

Because more throttle opening angle means that more air-fuel mixture will intake into the cylinder. As a result of lower heating value of ethanol, the power areas for ethanol falls under the E85 areas.

The different brake power areas are entirely due to the fuel's chemical content. The maximum brake power value is about $10 \%$ higher for E85 than ethanol. It is observed from the maps that the maximum power density of E85 is higher than ethanol.

As seen in Fig. 5, the brake specific fuel consumption (BSFC) areas have roughly a 
parabolic shape making its minimum at about 2000-3000 rpm for ethanol and E85.

When the throttle opening angle increases, the BSFC decrease. It is known that the lowest specific fuel consumption is about $270 \mathrm{~g} / \mathrm{kWh}$ for spark ignition engines for gasoline usage [23].

From this point of view, the usage of E85 is closer to this definition. The BSFC for E85 is lower than ethanol when maximum torque area is achieved. When comparing the maps for all operating conditions (throttle angles and engine speeds) about the BSFC, the usage of E85 is much more advantageous. The fuel consumption rate and rising tendency in ethanol is faster than E85 due to the increase in throttle opening angles and engine speeds.

Brake mean effective pressure (BMEP) area maps are plotted in Fig. 6 for ethanol and E85. BMEP is a function of the air-fuel mixture taken into the cylinder. For this reason, BMEP decreases with increasing engine speed and increases with increasing the throttle opening angle. The BMEP values are higher for usage of E85 in the engine than ethanol.

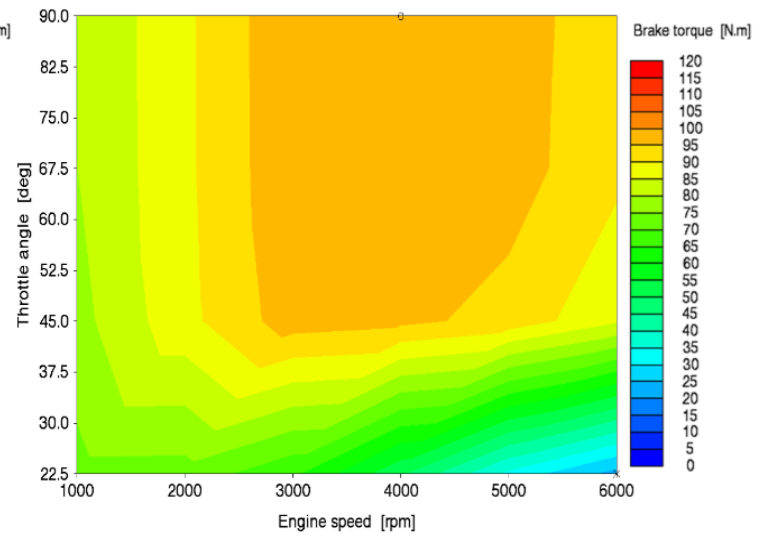

b. E85

Figure 3. Ethanol - E85 brake torque maps
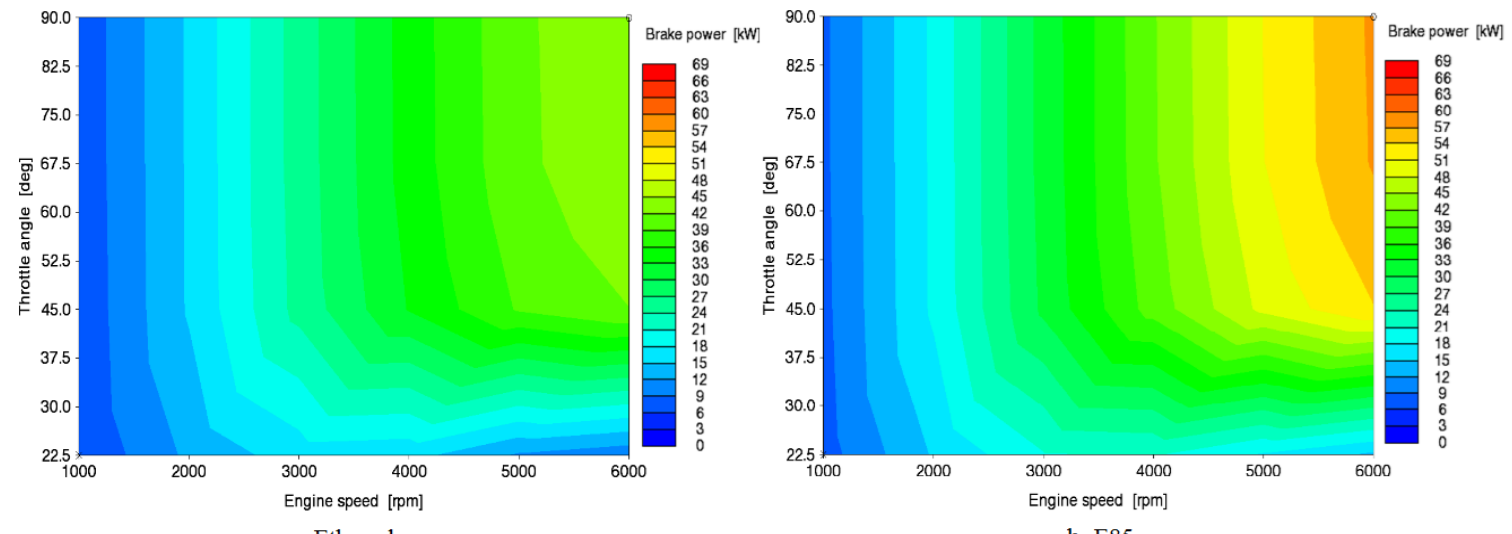

Figure 4. Ethanol - E85 brake power maps
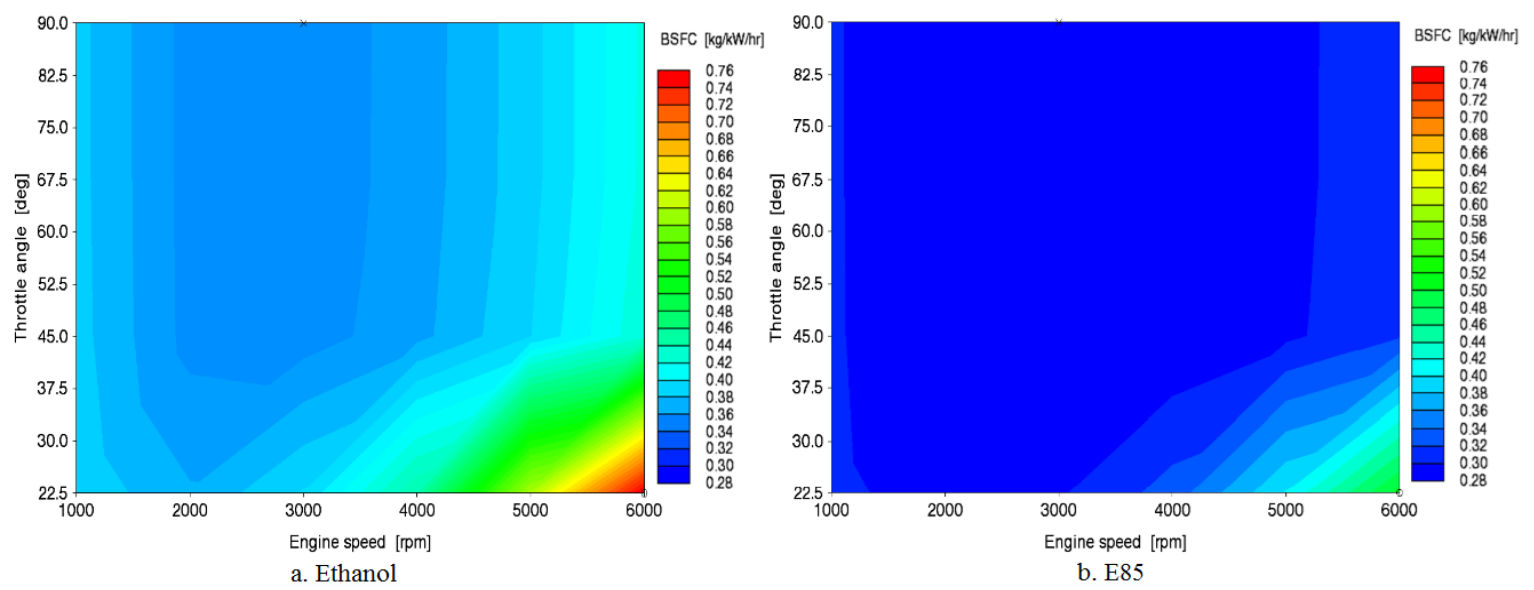

Figure 5. Ethanol - E85 brake specific fuel consumption maps 

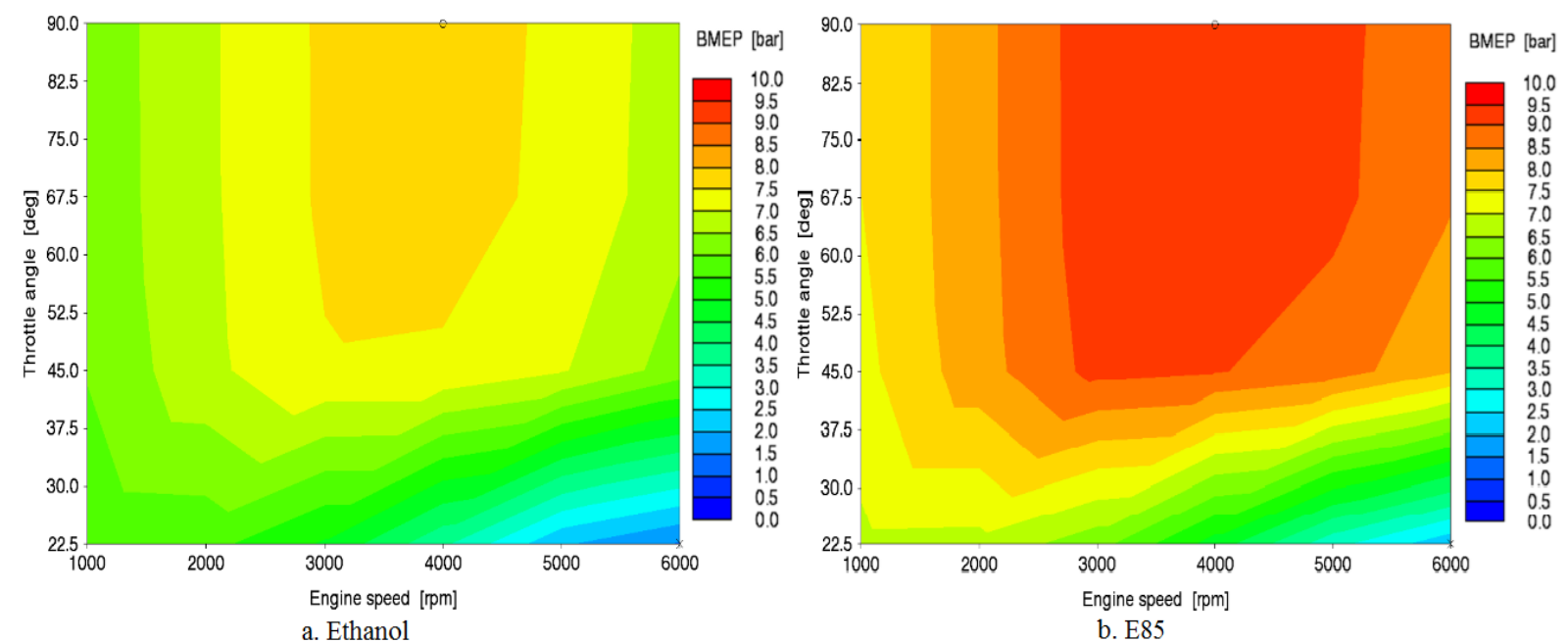

Figure 6. Ethanol - E85 brake mean effective pressure maps
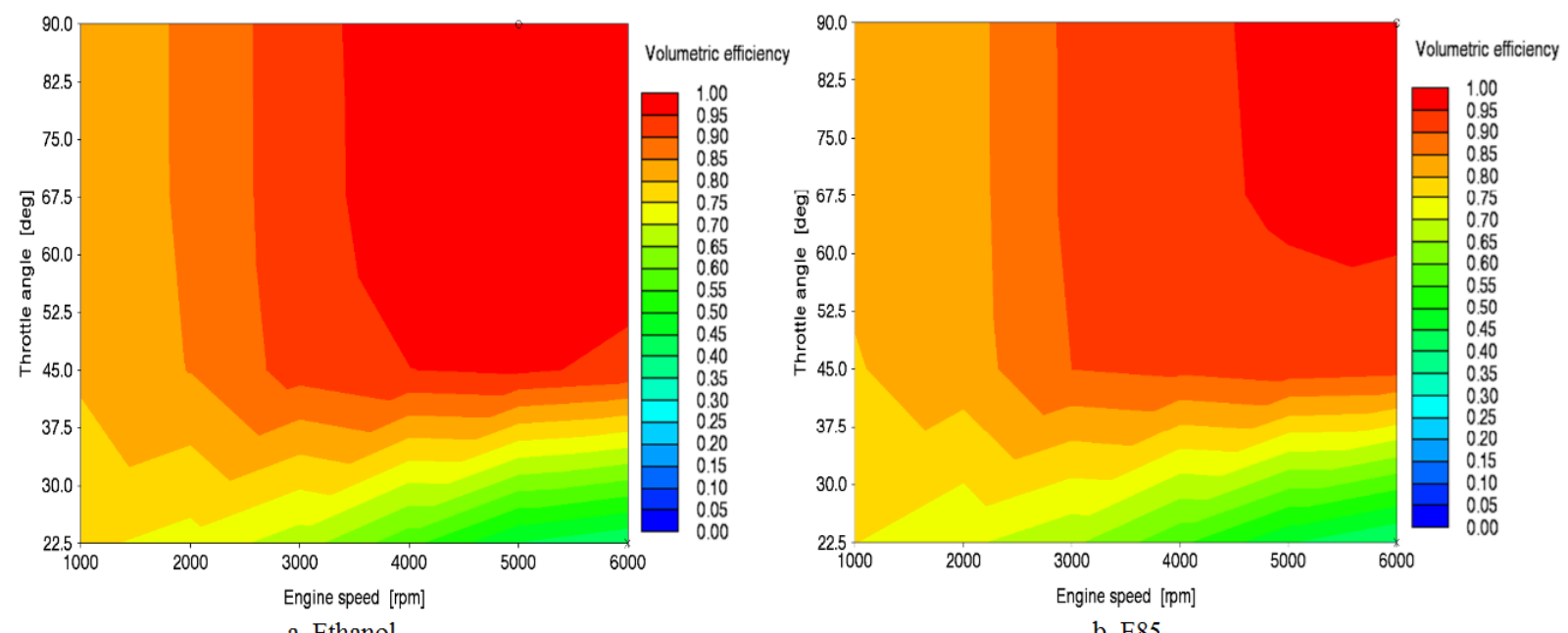

Figure 7. Ethanol - E85 volumetric efficiency maps
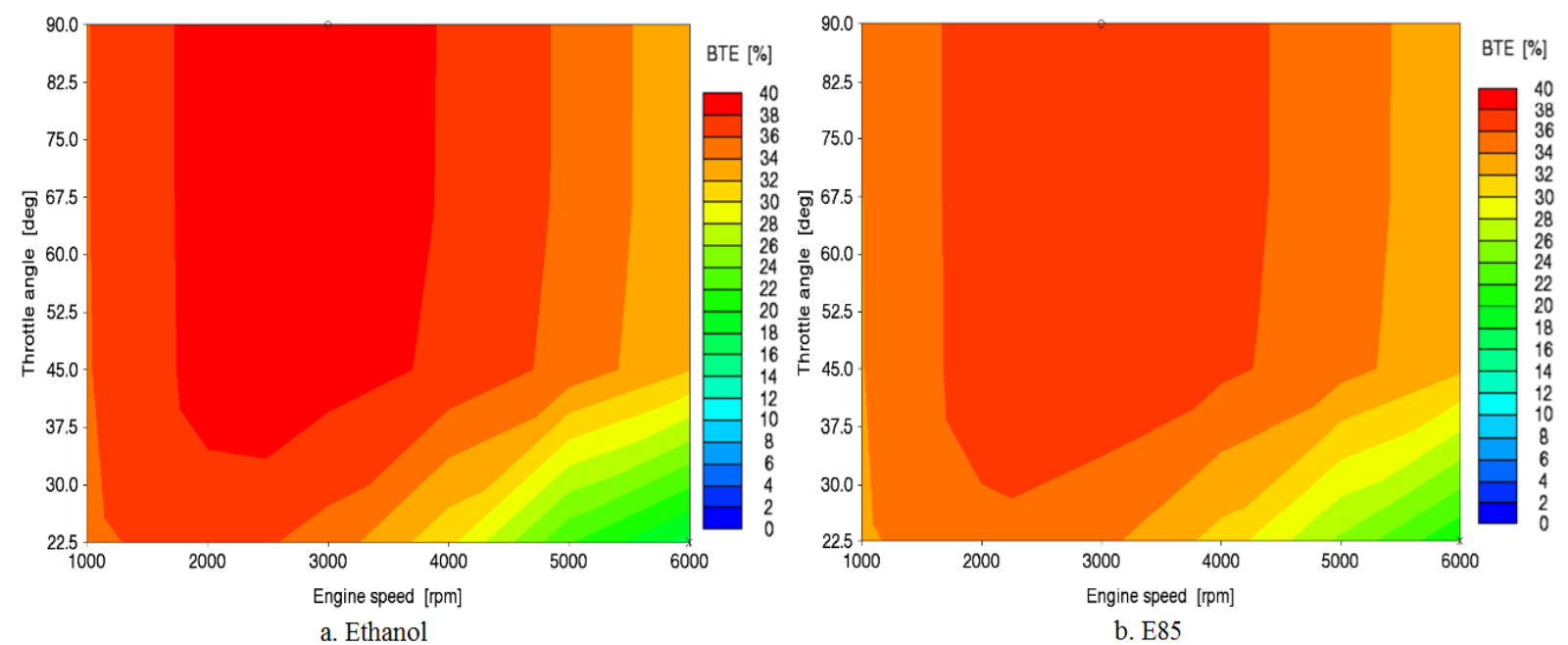

Figure 8. Ethanol - E85 brake thermal efficiency maps

For the considered range of engine speed, the average BMEP level for ethanol is less than E85 since the lower heating value of ethanol is lower than E85. The high pressure build-up area range is higher for E85 than ethanol. As mentioned in previous paragraphs, torque maps also support this situation.
Figure 7 shows that the volumetric efficiency maps for ethanol and E85, respectively. The volumetric efficiency increases with the engine speed and throttle opening angle. The volumetric efficiency maps are following similar trendily areas. These maps values are consistent with reported approximately 
volumetric efficiency of $75-90 \%$ for gasoline usage in a natural aspirated spark ignition engine [24].

As also plotted with map curves in Fig. 8, brake thermal efficiencies (BTE) are about $35-40 \%$ on the maps. Combustion efficiency decreases at high speed which effects on the direction of decreasing BTE. Brake thermal efficiency is a function of combustion mechanisms, $\mathrm{H} / \mathrm{C}$ ratio and lower heating value. The $\mathrm{H} / \mathrm{C}$ ratio of ethanol and $\mathrm{E} 85$ are higher than gasoline. Therefore, the brake thermal efficiencies are higher than gasoline because brake thermal efficiency is about thirty percent as expected for a typical natural aspirated spark ignition engine [23]. For compare E85 with ethanol; the lower heating value of E85 is approximately $8.4 \%$ higher than ethanol. However, the $\mathrm{H} / \mathrm{C}$ ratio of E85 is approximately $3.9 \%$ lower than ethanol. The high brake thermal efficiency areas for ethanol usage are lower than for the E85.

Another point of view, high brake thermal efficiency is observed at higher speeds when using E85. The usage of ethanol and E85 increase the brake thermal efficiency of the engine.

\section{Conclusion}

The method of mapping for internal combustion engines is helpful in evaluating at any operating point or determining ideal operating areas.

In this study, a sequential spark ignition engine performance parameters were determined for ethanol and E85 fuels at different throttle angles by using a 1-D model. The results from the performance maps are listed below.

The brake torque and brake power for ethanol are less than E85 for all operating conditions (throttle angles and engine speeds) since the lower heating value of ethanol is about $10 \%$ less than E85.

The BSFC for E85 is lower than ethanol and BSFC of E85 is closer to typical values in the literature of spark ignition engines for gasoline usage.

The BMEP values are higher for usage of E85 in the engine than ethanol. Similarly, the average BMEP level for ethanol is less than E85 since the lower heating value of ethanol is lower than E85.

The volumetric efficiency maps are following similar trendily areas and consistent with approximately volumetric efficiency of gasoline usage in a natural aspirated spark ignition engine reported in the literature.

Brake thermal efficiencies for ethanol and E85 are about $35-40 \%$ on the maps. The $\mathrm{H} / \mathrm{C}$ ratio of ethanol and E85 are higher than gasoline, therefore brake thermal efficiencies are higher than traditional Otto engines with gasoline usage $(\sim 30 \%)$.

As a result of the study, E85 has been observed to perform better than ethanol usage for the Honda L13A4 i-DSI that the engine designed for the usage of gasoline. Engine performance values can be increased with appropriate ethanol-gasoline mixture ratios and adjusted to engine control parameters (ignition advance, injection time, injection type, etc.).

\section{References}

1. RFA (Renewable Fuels Association). Leading the U.S. ethanol industry. 2016.http://www.ethanolrfa.org/resources/indu stry/statistics/\#1454099103927-61e598f77643.

2. Johansen, L. C. R., Hemdal, S. and Denbratt, I. "Comparison of E10 and E85 Spark Ignited Stratified Combustion and Soot Formation." Fuel, 205, 11-23, 2015.

3. Sarjovaara, T. and Larmi, M. "Dual Fuel Diesel Combustion with an E85 Ethanol/Gasoline Blend." Fuel, 139, 704-714, 2015.

4. Türköz, N., Erkuş, B., Karamangil, M. İ., Sürmen, A. and Arslanoğlu, N. "Experimental Investigation of the Effect of E85 on Engine Performance and Emissions Under Various Ignition Timings." Fuel, 115, 826-832, 2014.

5. Sarjovaara, T., Larmi, M. and Vuorinen, V. "Effect of Charge Air Temperature on E85 Dual-Fuel Diesel Combustion." Fuel, 153, 6-12, 2015.

6. Wang, C., Janssen, A., Prakash, A., Cracknell, R. and $\mathrm{Xu}, \mathrm{H}$. "Splash Blended Ethanol in a Spark Ignition Engine-Effect of RON, Octane Sensitivity and Charge Cooling." Fuel, 196, 21-31, 2017.

7. Huang, Y., Hong, G. and Huang, R. "Investigation to Charge Cooling Effect and Combustion Characteristics of Ethanol Direct Injection in a Gasoline Port Injection Engine." Applied Energy, 160, 244-254, 2015. 
8. Phuangwongtrakul, S., Wechsatol, W., Sethaput, T., Suktang, K. and Wongwises, S. "Experimental Study on Sparking Ignition Engine Performance for Optimal Mixing Ratio of Ethanol-Gasoline Blended Fuels." Applied Thermal Engineering, 100, 869-879, 2016.

9. Nakata, K., Utsumi, S., Ota, A., Kawatake, K., Kawai, T., and Tsunooka, T. "The Effect of Ethanol Fuel on a Spark Ignition Engine." SAE Technical Paper, No. 2006-01-3380, 2006.

10. Li, Y., Gong, J., Deng, Y., Yuan, W., Fu, J., and Zhang, B. "Experimental Comparative Study on Combustion, Performance and Emissions Characteristics of Methanol, Ethanol and Butanol in a Spark Ignition Engine." Applied Thermal Engineering, 115, 53-63, 2017.

11. Hamilton, L. J., Rostedt, M. G., Caton, P. A., and Cowart, J. S. "Pre-Ignition Characteristics of Ethanol and E85 in a Spark Ignition Engine." SAE International Journal of Fuels and Lubricants, 1(1), 145-154, 2009.

12. Park, C., Choi, Y., Kim, C., Oh, S., Lim, G., and Moriyoshi, Y. "Performance and Exhaust Emission Characteristics of a Spark Ignition Engine Using Ethanol and Ethanol-Reformed Gas." Fuel, 89(8), 2118-2125, 2010.

13. Jin, D., Choi, K., Myung, C. L., Lim, Y., Lee, J., and Park, S. "The Impact of Various Ethanol-Gasoline Blends on Particulates and Unregulated Gaseous Emissions Characteristics from a Spark Ignition Direct Injection (SIDI) Passenger Vehicle." Fuel, 209, 702-712, 2017.

14. Mahle GmbH. "Pistons and Engine Testing." ATZ/MTZ-Fachbuch, 2012.

15. Migita, H., Amemiya T., Yokoo K., and Iizuka, Y. "The New 1.3-Liter 2-Plug Engine for the 2002 Honda Fit." JSAE Review, 23, 507511, 2002.

16. Nakayama, Y., Suzuki, M., Iwata, Y., and Yamano, J. "Development of a 1.3 1t 2-Plug Engine for the 2002 Model Fit." Honda R\&D Technical Review, 13, 43-52, 2001.

17. Woschni, G. "Universally Applicable Equation for the Instantaneous Heat Transfer Coefficient in the Internal Combustion Engine." SAE Paper, 1967.

18. Vibe, I. I. "Semi-Empirical Expression for Combustion Rate in Engines." In Proceedings of Conference on piston engines. USSR Academy of Sciences Moscow 185-191, 1956.
19. Newhall, H. K. "Kinetics of EngineGenerated Nitrogen Oxides and Carbon Monoxide." Proceedings of 12th International Symposium on Combustion 603-613, 1968.

20. Cheng, W. K., Hamrin, D., Heywood, J. B., Hochgreb, S., Min,K., and M. Norris. "An Overview of Hydrocarbon Emissions Mechanisms in Spark-Ignition Engines." SAE Paper, 1993.

21. Fenimore, C. P. "Formation of Nitric Oxide in Premixed Hydrocarbon Flames." Proceedings of the Combustion Institute, 13-373, 1970.

22. Miller, R., Davis, G., Lavoie, G., Newman, C., and Gardner, T. "A Super-Extended Zel'dovich Mechanism for NOx Modeling and Engine Calibration." SAE Technical Paper, No. 980781, 1998.

23. Heywood, J. B., Internal Combustion Engine Fundamentals, McGraw-Hill College, 1988.

24. Pulkrabek, W. W. Engineering Fundamentals of the Internal Combustion Engine, Pearson Higher Edition, 2013. 